\title{
Global Pathogen Distributions: A Win-Win for Disease Ecology and Biogeography
}

The breakdown of barriers to trade, exploration, military invasion, colonization, and emigration has facilitated ongoing shifts in human pathogen distributions for millennia, often with deadly consequences. We all know the story of Cortez's arrival in the New World and subsequent introduction of novel pathogens, like smallpox, which decimated the Amerindians (McNeill, 1989). Many pathogens endemic to specific regions only 500 years ago were broadly distributed around the world by the 20th century (Smith et al., 2007). With the rise of public health initiatives and preventative medicine, many of these diseases were eradicated or brought under control by the mid1900s. Today, a new list of pathogens is replacing the old as the timeless process of emergence continues.

At the advent of a century threatened by global pandemics linked to environmental change and population growth, a thorough understanding of the patterns and processes that govern the geographic distribution of human pathogens is more critical than ever. This issue's special feature on "Disease Biogeography" illustrates how the tools and concepts from traditional biogeography can inform disease ecology and evolution. Also valuable, though not fully explored here, is the reverse-how the study of pathogens and the diseases they cause can advance the field of biogeography.

For centuries, biogeographic principles informed scientists of where biota occurs and why. To date, however, few biogeographers included human pathogens in their search for general patterns in the distribution of life on Earth. In part, this is due to a lack of synthesized historical, epidemiological, and geographical data on the $>1400$ pathogens that infect humans (Woolhouse and GowtageSequeira, 2005). Compared to macro-organisms, we know relatively little about whether human pathogens conform to the more common biogeographic patterns. Whereas hundreds of publications have documented Rapoport's Rule for macro-organisms, only a few have considered whether these latitudinal gradient patterns hold for human pathogens (Guernier et al., 2004; Jones et al., 2008; Guernier and Guegan, 2009). Biotic homogenization, the process by which species invasions and extinctions increase the taxonomic, genetic, or functional similarity of disparate communities over a specified time interval, is apparent in plant and animal assemblages worldwide, but only recently documented for human pathogens (Smith et al., 2007; Olden, 2008). While Island Biogeography Theory has been invoked hundreds of times to predict species richness in insular communities, it has not been fully employed to explain disease occurrence on the world's island nations (MacArthur and Wilson, 1967; Cliff and Haggett, 1995).

To the extent that pathogens conform to the biogeographic relationships widely documented for plants and animals, they will uphold the generality of empirical patterns and support hypotheses that myriad taxonomic groups share universal attributes. Alternatively, if pathogens exhibit exceptions to widely documented biogeographic patterns, then this will help to identify the unique features that have influenced their global distributions.

Studying global pathogen distributions using the same techniques applied to plants and animals can be a win-win for disease ecology and traditional biogeography. For example, the latitudinal gradient in species richness has been explained by a number of different hypotheses including temperature variability, differential rates of speciation or extinction, and the consequence of past climate cycles (Lomolino et al., 2006). Recent studies have explored 
the global distribution of invasive species in order to discriminate between hypotheses postulated for the pattern (i.e., Sax, 2001). Unlike native species, invaders are recent arrivals in a region, and so their distributions are limited by conditions currently or recently in existence. For example, nonnative species of major taxonomic groups demonstrate qualitatively similar latitudinal gradients in richness to native species (Sax, 2001), therefore ruling out historical mechanisms as general drivers of the pattern (i.e., speciation or glaciation).

Given the growing interest in invasive species biogeography, it is surprising that the tools of the field have not been more widely adopted by scientists studying global pathogen distributions. Indeed, there is a noted analogy between native and nonnative species and nonemerging and emerging pathogens (Drake, 2005), such that the now vast body of research on the former should offer both practical and academic value to the study of the latter.

For example, if both nonemerging and emerging pathogens conform to the latitudinal species richness gradient, then we can rule out historical mechanisms (i.e., differential rates of pathogen evolution) between geographic regions as a driving force. If, however, nonemerging pathogens conform to the pattern but emerging pathogens exhibit a peak in richness outside tropical latitudes, this may indicate the presence of a newly influential condition. Now that substantial data is available on the global distributions of human pathogens, it is possible to adapt the techniques of invasive species biogeography to investigate the general factors driving global pathogen distributions.

Guernier et al. (2004) showed that human pathogens conform to the latitudinal gradient of species richness. While they did not distinguish between those emerging and nonemerging, their dataset was very likely dominated by the latter. More recently, Jones et al. (2008) implied that pathogen emergence events-the first temporal origination of an emerging human pathogen-exhibit a peak in richness in temperate latitudes, but this finding was not fully explored by the authors.

There are many plausible explanations for potentially conflicting latitudinal patterns exhibited by nonemerging and emerging pathogens: variation in national reporting efforts or public health systems, for example, or environmental, demographic, or socioeconomic influences. Unfortunately, it is impossible to know without a system- atic comparison of the two groups using comparable data (i.e., emerging and nonemerging pathogen occurrences from the same time period). Nevertheless, discrepancies between the global distributions of these two pathogen groups suggest that each is governed by unique mechanisms. Identifying these and other mechanisms responsible for the biogeographic patterns exhibited by human pathogens will benefit disease ecologists, inform global public health initiatives, and help to refine the list of general mechanisms driving the biogeographic patterns of all life on Earth.

Katherine F. Smith

Ecology and Evolutionary Biology,

Brown University, Providence, RI

e-mail: Katherine_Smith@brown.edu

\section{REFERENCES}

Cliff AD, Haggett AD (1995) The epidemiological significance of islands. Health \& Place 1:199-209

Drake JM (2005) Risk analysis for invasive species and emerging infectious diseases: concepts and applications. American Midland Naturalist 153:4-19

Guernier V, Guégan J-F (2009) May Rapoport's rule apply to human associated pathogens? EcoHealth. doi:10.1007/s10393010-0290-5

Guernier V, Hochberg ME, Guegan JF (2004) Ecology drives the worldwide distribution of human diseases. PLoS Biology 2:740 746

Jones KE, Patel N, Levy M, Storeygard A, Balk D, Gittleman JL, et al. (2008) Global trends in emerging infectious diseases. Nature 451:990-993

Lomolino MV, Brown JH, Riddle BR (2006) Biogeography, Sunderland, MA: Sinauer Associates

MacArthur RH, Wilson EO (1967) The Theory of Island Biogeography, Princeton, NJ: Princeton University Press

McNeill WH (1989) Plagues and Peoples, New York: Anchor Books

Olden JD (2008) Biotic homogenization. In: Encyclopedia of Life Sciences (ELS), Chichester, UK: Wiley

Sax DF (2001) Latitudinal gradients and geographic ranges of exotic species: implications for biogeography. Journal of Biogeography 28:139-150

Smith KF, Sax DF, Guernier V, Guegan JF (2007) Globalization of human infectious diseases. Ecology 88:1903-1910

Woolhouse MEJ, Gowtage-Sequeira S (2005) Host range and emerging and reemerging pathogens. Emerging Infectious Disease 11:1842-1847

Published online: March 31, 2010 